\title{
Cayler Cardio-Facial Syndrome: An Uncommon Condition in Newborns
}

\author{
Sunil Jayaram Pawar ${ }^{1}$; Deepak Kumar Sharma ${ }^{2, "}$; Sela Srilakshmi ${ }^{1}$; Suguna Reddy Chejeti \\ ${ }^{1}$; Aakash Pandita $^{2}$ \\ ${ }_{1}^{1}$ Department of Paediatrics, Durgabai Deshmukh Research Center and Hospital, Hyderabad, Andhra Pradesh, India \\ ${ }^{2}$ Department of Neonatology, Fernandez Hospital, Hyderguda, Hyderabad, India \\ *Corresponding author: Deepak Kumar Sharma, Department of Neonatology, Fernandez Hospital, Hyderguda, Hyderabad, India. Tel: +91-9462270002, E-mail: dr.deepak.rohtak@ \\ gmail.com
}

Received: July 26, 2014; Accepted: January 30, 2015

\begin{abstract}
Introduction: Cayler cardio-facial syndrome is a rare syndrome associated with asymmetric crying faces with congenital heart disease. We report a newborn that was diagnosed as case of Cayler Cardio-facial syndrome based on clinical features and was confirmed with FISH analysis.

Case Presentation: A term male baby, born to non-consanguineous couple through normal vaginal delivery was diagnosed to have asymmetric crying faces with deviation of angle of mouth to left side at the time of birth. The baby had normal faces while sleeping or silent. Mother was known case of hypothyroidism and was on treatment. Baby was diagnosed as case of Cayler Cardio-facial Syndrome and was investigated with echocardiogram, brain ultrasound, total body X-ray examination, X-ray of cervico-thoracic vertebral column and fundus examination. Echocardiogram showed muscular VSD, brain ultrasound was normal and fundus examination showed tortuous retinal vessels. Whole body X-ray and lateral X-ray of cervico-thoracic vertebral column were not suggestive of any skeletal abnormalities. The other associated malformation was right ear microtia. Baby FISH karyotype analysis showed deletion of 22q11.2 deletion. Baby was discharged and now on follow-up.

Conclusions: Cayler syndrome is a rare syndrome which must be suspected if a baby has asymmetrical cry pattern and normal facies when baby sleeps. Patient must be evaluated with echocardiography to find out associated cardiac malformations. These infants should undergo FISH analysis for 22q11.2 deletion syndrome.
\end{abstract}

Keywords: Cayler Cardiofacial Syndrome; Congenital Heart Defect

\section{Introduction}

Cayler cardio-facial syndrome is a rare syndrome associated with asymmetric crying faces with congenital heart disease. The syndromes which are to be differentiated include Goldenhar syndrome, Moebius syndrome, Craniofacial microsomia, Velocardiofacial, DiGeorge syndrome or rarely with Opitz GBBB syndrome (1). We report a newborn that was diagnosed as case of Cayler Cardio-facial syndrome based on clinical features and was confirmed with FISH analysis.

\section{Case Presentation}

A term male baby was born to non-consanguineous couple, G2P1L1 mother through normal vaginal delivery with birth weight of $2.8 \mathrm{~kg}$. Baby had normal Apgar score of 7/8/9. Antenatal scan was normal and mother was known case of hypothyroidism and was on treatment with eltroxin. This was a spontaneous conception. Post natal course of baby was uneventful. At birth baby was diagnosed to have asymmetric crying faces with deviation of angle of mouth to left side (Figure 1). Baby had normal faces while sleeping or silent (Figure 2). There was no ab- normality in closing eyes while the sleeping. There were no cutaneous marker or any obvious malformation life cleft lip and palate except right ear microtia. There was no hemifacial microsomia, no epibulbar dermoid or other cranial nerve paralysis (ruling out Goldenhar, Moebius and craniofacial microsomia). There was no family history and the examination of parents was normal. Baby was investigated with echocardiogram, brain ultrasound, and whole body X-ray, whole spine lateral X-ray column and fundus examination. Echocardiogram was suggestive of muscular ventricular septal defect $(2.2 \mathrm{~mm})$, brain ultrasound was normal and fundus examination showed tortuous retinal vessels. Blood investigation showed hypocalcemia (total value $7 \mathrm{mg} / \mathrm{dL}$ ) and hypoparathyroidism (14 pg/mL). Total body X ray examination and X-ray of cervico-thoracic vertebral column were not suggestive of any skeletal abnormalities which ruled out Goldenhar syndrome. Baby was investigated with FISH analysis which showed deletion of 22q11.2 deletion. Eye exam, hearing test, immunology tests, and renal ultrasound of the infant were normal. The infant was discharged and now on follow up. 


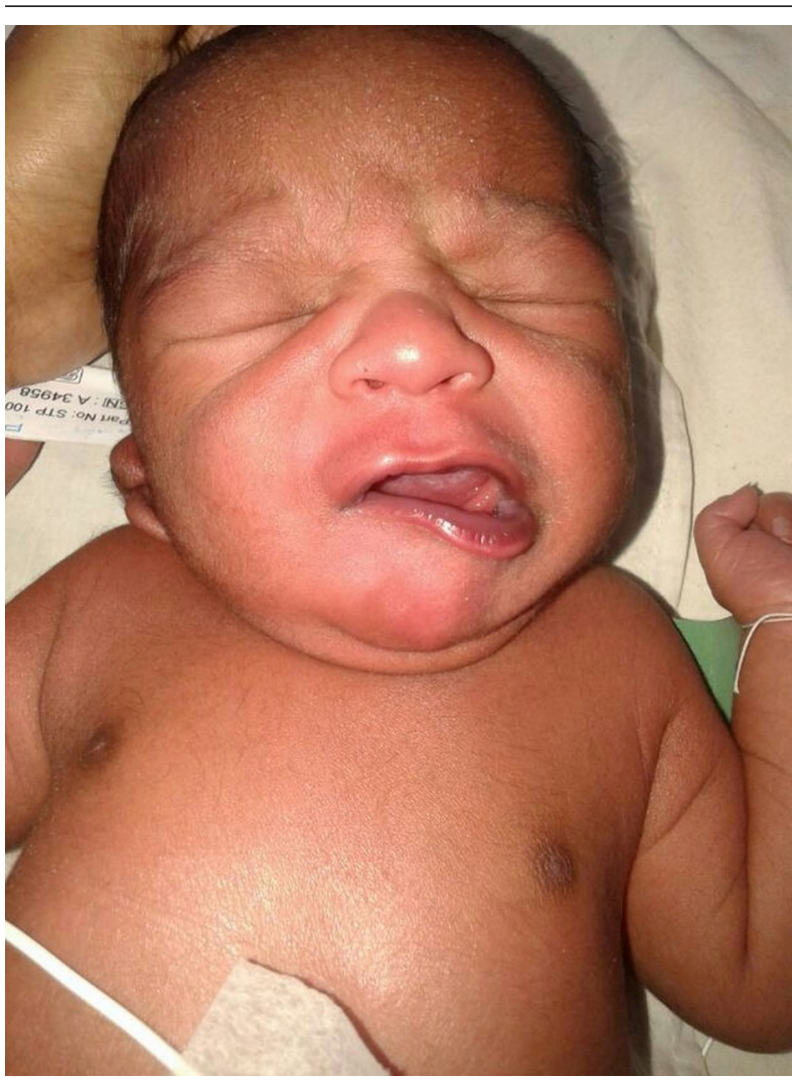

Figure 1. Asymmetry of Face With Deviation of Mouth Toward Left When the Neonate is Crying

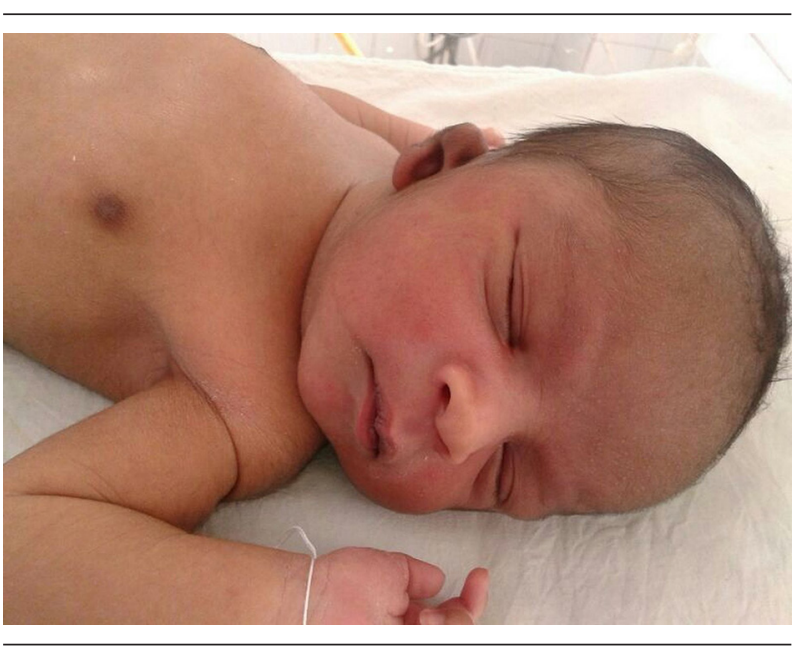

Figure 2. No Asymmetry of Face While Sleeping

\subsection{Differential Diagnosis}

Congenital facial palsy, Moebius Syndrome, Goldenhar syndrome.

\section{Discussion}

Cayler syndrome, also known as "Asymmetric crying faces with cardiac defects or hypoplasia of the depressor anguli oris muscle with cardiac defects" is a rare disorder. Its characteristic features include congenital heart defects and absence or hypoplasia of depressor angular oris muscle, one of the muscles that controls the movements of the lower lip (2). The disorder is congenital and is usually noticed by the mother when the newborn cries or smiles. On the affected side of face, lower lip cannot be drawn down and outward because of the defect in depressor angular oris muscle (3).

Asymmetric crying faces can occur as an isolated event caused by the hypoplasia or agenesis of depressor angular oris muscle of the lip. It is generally noticed when a newborn cries and his affected lower lip is pulled downward to one side and there is absence of movement of the lip to contralateral side. The affected newborns have no difficulty in closing the eyes and have normal forehead wrinkling movements which are the differentiating features from facial nerve palsy. Sucking movements are normal with no drooling of saliva. However, Cayler reported the association of this trait with congenital heart disease and called it cardio-facial syndrome, subsequently called Cayler Cardio facial syndrome (1). Cayler Cardio-facial syndrome was first linked to $22 \mathrm{q}$ deletion syndrome in 1994. Children diagnosed with Cayler Cardio-facial syndrome have the underlying condition called 22q11.2 deletion syndrome in which there is missing of small part of the chromosome 22 (4).

The clinical features and other system involvement other than abnormality of depressor angular oris muscle include (5-7), Cardiac malformations like ventricular septal defects, tetralogy of Fallot, atrial septal defects, coarctation of aorta, cardiomyopathy, pulmonary stenosis, hypoplastic left heart syndrome, persistent left superior vena cava, tricuspid regurgitation, transposition of great arteries, total anomalous pulmonary venous return, aortic regurgitation, mitral stenosis, tricuspid atresia, right aortic arch, truncus arteriosus , patent ductus arteriosus. The most common associated malformations are, Microcephaly, Micrognathia, Micropthalmos, Mental retardation, VACTER association (vertebral defects, imperforate anus, tracheo esophageal fistula, and radial and renal dysplasia), Genitourinary abnormalities like hydronephrosis, renal hypoplasia, vesicoureteral reflux, hypospadias), Spinal defects like spina bifida, Limb anomalies like syndactyly and polydactyly.

The cause of hypoplasia of the depressor anguli oris muscle still remains to be eluded though past study postulated intrauterine molding or subclinical viral infections as the cause but it needs to be proved in present time (7). This deletion manifests as the medical problem which are generally encountered in children with this syndrome. Parents are to be counselled for the long term outcome as deletion $22 \mathrm{q}$ has been found to be responsible for learning difficulties and mental retardation (8). The workup must be done to distinguish 22q11 deletion of the oculo-auriculo-vertebral spectrum (Goldenhar syndrome). It should include (9): Chromosomal or DNA stud- 
ies, Ophthalmologic evaluation, X-ray of cervico-thoracic vertebral column.

Recently there has been a case report of Cayler cardio facial syndrome associated with situs inversus totalis in a newborn showing the importance of echocardiographic evaluation of the neonates that are diagnosed as Cayler cardio facial syndrome (10). In a rare case report Cayler cardio facial syndrome was associated with anotia and unilateral facial nerve palsy (11).

\subsection{Conclusions}

1. Cayler syndrome is a rare case which must be suspected if a baby has asymmetrical cry pattern and normal facies when baby sleeps. 2. Patient must be evaluated with echocardiography to find out associated cardiac malformations. 3. Hearing assessment must be done in all such babies so that early intervention can be done if there is some hearing abnormality.

\section{Authors' Contributions}

Sunil Jayaram Pawar, Deepak Kumar Sharma, Sela Srilakshmi: Substantial contributions to the conception or design of the work and the acquisition, analysis or interpretation of data for the work. Suguna Reddy Chejeti, Aakash Pandita: Drafting the work or revising it critically for important intellectual content. Sunil Jayaram Pawar, Deepak Kumar Sharma; Sela Srilakshmi, Suguna Reddy Chejeti, Aakash Pandita: Final approval of the version to be published. Sunil Jayaram Pawar, Deepak Kumar Sharma, Sela Srilakshmi, Suguna Reddy Chejeti, Aakash Pandita, Agreement to be accountable for all aspects of the work in ensuring that questions related to the accuracy or integrity of any part of the work are appropriately investigated and resolved.

\section{References}

1. Cardiofacial syndrome. Congenital heart disease and facial weakness, a hitherto unrecognized association. Cayler GG. Arch Dis Child. 1969;44(233):69. [PubMed: 5765991]

2. Seven new cases of Cayler cardiofacial syndrome with chromosome 22q11.2 deletion, including a familial case. Bawle EV, Conard J, Van Dyke DL, Czarnecki P, Driscoll DA. Am J Med Genet. 1998;79(5):406.

3. Asymmetric crying facies in the 22q11.2 deletion syndrome: implications for future screening. Pasick C, McDonald-McGinn DM, Simbolon C, Low D, Zackai E, Jackson O. Clin Pediatr (Phila). 2013;52(12):1144.

4. Clinical manifestations of Deletion 22q11.2 syndrome (DiGeorge/ Velo-Cardio-Facial syndrome). Digilio M, Marino B, Capolino R, Dallapiccola B. Images Paediatr Cardiol. 2005;7(2):23.

5. [Clinical features and follow-up study of neonatal asymmetric crying facies]. Lu CQ, Zhuang XL, Chu C, Jiang H, Wang JM. Zhongguo Dang Dai Er Ke Za Zhi. 2012;14(12):913.

6. Unusual association of congenital hypoplasia of the depressor anguli oris muscle (DAOM). Kumar KJ, Chavan A, Shetty C, Sharma R. Indian J Pediatr. 2013;80(6):519.

7. Asymmetric crying facies and associated congenital anomalies: prospective study and review of the literature. Lahat E, Heyman E, Barkay A, Goldberg M. J Child Neurol. 2000;15(12):808.

8. The 22q11.2 deletion: screening, diagnostic workup, and outcome of results; report on 181 patients. McDonald-McGinn DM, LaRossa D, Goldmuntz E, Sullivan K, Eicher P, Gerdes M, et al. Genet Test. 1997;1(2):99.

9. Oculoauriculovertebral spectrum: report of nine familial cases with evidence of autosomal dominant inheritance and review of the literature. Vendramini-Pittoli S, Kokitsu-Nakata NM. Clin Dysmorphol. 2009;18(2):67.

10. Cayler cardiofacial syndrome with situs inversus totalis. Rai B, Mallick D, Thapa R, Biswas B. Eur J Pediatr. 2014;173(12):1675.

11. Anotia and facial palsy: unusual features of cardiofacial syndrome. Girisha KM, Phadke SR. Indian J Pediatr. 2005;72(6):525. 